\title{
Hesitancy in COVID-19 vaccine uptake and its associated factors among the general adult population: a cross-sectional study in six Southeast Asian countries
}

\author{
Roy Rillera Marzo 1,2,3, Waqas Sami ${ }^{4,5}$, Md. Zakiul Alam6 ${ }^{6}$, Swosti Acharya ${ }^{7}$, Kittisak Jermsittiparsert ${ }^{8}$, \\ Karnjana Songwathana ${ }^{9}$, Nhat Tan Pham ${ }^{10,11}$, Titik Respati ${ }^{12}$, Erwin Martinez Faller ${ }^{13}$, \\ Aries Moralidad Baldonado ${ }^{14}$, Yadanar Aung ${ }^{15,16}$, Sharmila Mukund Borkar ${ }^{17}$, Mohammad Yasir Essar ${ }^{18^{*}}$, \\ Sunil Shrestha ${ }^{19}$ and Siyan Yi $20,21,22$
}

\begin{abstract}
Background: Vaccines are effective and reliable public health interventions against viral outbreaks and pandemics. However, hesitancy regarding the Coronavirus disease (COVID-19) vaccine is evident worldwide. Therefore, understanding vaccination-related behavior is critical in expanding the vaccine coverage to flatten the infection curve. This study explores the public perception regarding COVID-19 vaccination and identifies factors associated with vaccine hesitancy among the general adult populations in six Southeast Asian countries.

Methods: Using a snowball sampling approach, we conducted a descriptive cross-sectional study among 5260 participants in Indonesia, Malaysia, Myanmar, Philippines, Thailand, and Vietnam between February and May 2021. Binary logistic regression analysis with a backward conditional approach was applied to identify factors associated with COVID-19 vaccine hesitancy.

Results: Of the total, 50.6\% were female, and the median age was 30 years (range: 15-83 years). The majority of the participants believed that vaccination effectively prevents and controls COVID-19 (81.2\%), and 84.0\% would accept COVID-19 vaccines when they become available. They agreed that health providers' advice (83.0\%), vaccination convenience (75.6\%), and vaccine costs (62.8\%) are essential for people to decide whether to accept COVID-19 vaccines. About half (49.3\%) expressed their hesitancy to receive the COVID-19 vaccines. After adjustment for other covariates, COVID-19 vaccine hesitancy was significantly associated with age, residential area, education levels, employment status, and family economic status. Participants from Indonesia, Myanmar, Thailand, and Vietnam were significantly more likely to express hesitancy in receiving COVID-19 vaccines than those from Philippines.
\end{abstract}

Conclusions: In general, participants in this multi-country study showed their optimistic perception of COVID-19 vaccines' effectiveness and willingness to receive them. However, about half of them still expressed their hesitancy in getting vaccinated. The hesitation was associated with several socioeconomic factors and varied by country.

\footnotetext{
*Correspondence: yasir.essar@gmail.com

${ }^{18}$ Kabul University of Medical Sciences, Kabul, Afghanistan

Full list of author information is available at the end of the article
}

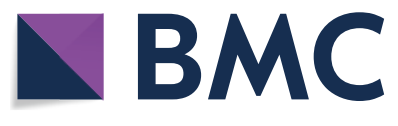

(c) The Author(s) 2022. Open Access This article is licensed under a Creative Commons Attribution 4.0 International License, which permits use, sharing, adaptation, distribution and reproduction in any medium or format, as long as you give appropriate credit to the original author(s) and the source, provide a link to the Creative Commons licence, and indicate if changes were made. The images or other third party material in this article are included in the article's Creative Commons licence, unless indicated otherwise in a credit line to the material. If material is not included in the article's Creative Commons licence and your intended use is not permitted by statutory regulation or exceeds the permitted use, you will need to obtain permission directly from the copyright holder. To view a copy of this licence, visit http://creativecommons.org/licenses/by/4.0/. 
Therefore, COVID-19 vaccination programs should consider these factors essential for increasing vaccine uptake in the populations.

Keywords: Immunization, Pandemic, Vaccine hesitancy, Acceptance, Multi-country study, Southeast Asia

\section{Introduction}

The ongoing global pandemic of coronavirus disease 2019 (COVID-19) has already infected 257 million population and of them, 5.1 million already died . Both therapeutic and non-therapeutic measures were taken to flatten the numbers of COVID-19 confirmed cases and reduce the deaths. However, the non-pharmaceutical interventions taken worldwide to tackle the pandemic have become tranquil with time $[1,2]$. Therefore, it becomes essential to achieve herd immunity or implement effective vaccination. Achieving herd immunity for COVID-19 by natural means or allowing a large number of people to become infected will cause an unprecedented strain on healthcare resources and will also result in up to 30 million deaths worldwide [3]. Thus, mass vaccination has become the only way to manage COVID-19 transmission.

Vaccines other than COVID-19 are one of the most effective and reliable public health interventions ever implemented that prevent millions of deaths from viral infections every year [4-6]. Although anti-vaccination attitudes and associated misconceptions are prevalent worldwide $[7,8]$, vaccination programs have been developed and progressed significantly in the global health era. Currently, the vaccine from the Pfizer/BioNTech, the SII/Covishield and AstraZeneca/AZD1222 developed by AstraZeneca/Oxford, the Janssen/Ad26.COV 2.S developed by Johnson \& Johnson, the Moderna COVID-19 vaccine (mRNA 1273), the Sinopharm COVID-19 vaccine from China National Biotec Group, and the SinovacCoronaVac are listed for WHO Emergency Use Listing (EUL). All the vaccines have some sort of mild to moderate side effects, but all of them are safe and effective (60-95\%). COVID-19 vaccines save from not only infection but also severe illness and death. Though mass vaccination programs have already been started globally, the effectiveness of vaccination programs has been affected by a hesitancy to receive the vaccines in populations [9-11], where vaccine hesitancy is defined as the delay in acceptance or refusal of available vaccines [12].

The hesitancy regarding COVID-19 vaccines is prominently evident worldwide [13-15]. Studies have identified several factors associated with the COVID-19 vaccine hesitancy in different domains. The identified factors included various socioeconomic and demographic characteristics (e.g., age, sex, residence, income, occupation, and marital status) [14, 16-19] constructs of the health belief model $[20,21]$, constructs of theory of planned behavior and the
$5 \mathrm{c}$ psychological antecedents [20, 22], vaccines-related knowledge [14, 23, 24], attitude towards COVID-19 vaccination [14, 18, 24], conspiracy beliefs [14, 25-27], trust and confidence [9], COVID-19 preventive behavioral practices [28-30], and the perceived safety and side effects of the vaccines [31-34]. Despite vaccine hesitancy, the demand for vaccines increases over time, and disparities in vaccine access within and across the countries are remarkable [35]. Even though the primary drivers of vaccine hesitancy are often context-specific, there are some agreements that confidence and trust in the COVID-19 vaccine play a critical role in increasing vaccine acceptance $[9,36]$.

COVID-19 cases have been increasing in Southeast Asian countries [37], and the COVID-19 pandemic impacted the lives of everyone, including health care workers, in many ways, including mental health $[8,38-41]$. As of November 21, 2021, around 4.25, 2.82, 2.58, 2.06, 1.09, and 0.52 million confirmed cases have already been in Indonesia, Philippine, Malaysia, Thailand, Vietnam, Myanmar, respectively. The government of all the countries has been trying to mitigate the infection with several measures, including mass vaccination. Understanding vaccinationrelated behavior is critical in expanding the vaccine coverage to flatten the infection curve. Unfortunately, studies related to the COVID-19 vaccine hesitancy are limited in the context of these nations. As of November 21, 2021, the proportion of the general population fully vaccinated was $32.2 \%$ in Indonesia, $79.9 \%$ in Malaysia, $17.9 \%$ in Myanmar, 38.3\% in Philippines, 54.73\% in Thailand, and 39.6\% in Vietnam [37]. Though started with AstraZeneca in the first phase, Pfizer, Sinovac, and Covovax vaccines are available in east Asian countries. The hesitancy to receive the COVID-19 vaccine may pose critical challenges in the fight against the pandemic and the global shortage of vaccines. To address this gap, we conducted a multi-country study to assess the perception of the COVID-19 vaccine effectiveness, acceptance, and hesitancy in the context of Southeast Asian countries. We also explored factors associated with the hesitation in the vaccine uptake.

\section{Methods \\ Study design and sites}

This descriptive cross-sectional study was conducted in six Southeast Asian countries i.e., Indonesia, Malaysia, Myanmar, Philippines, Thailand, and Vietnam for 4 months from February to May 2021. 


\section{Participants and sampling}

The target participants were adult citizens from the participating countries aged 18 years and above, who could read and understand local languages or English. Due to the limitations in employing face-to-face methods during the outbreak, the survey was prepared in a Google form and disseminated to the participants using a snowball sampling method. First, we recruited 50 primary participants and asked them to share the questionnaire link to individuals in their social networks who met the inclusion criteria. We chose these social media platforms, because they are widely used across socio-demographic characteristics. The response rate ranged from $30-45 \%$.

\section{Data collection procedures}

We distributed the questionnaire using personal contacts using word of mouth or emails and through webbased applications and social media, such as Facebook, Instagram, LinkedIn, Telegram, Twitter, and WhatsApp. Participants were reminded to respond only once. We employed unique identifiers for use only in a single account by settings that allow only one response per user. In addition, the Google form will not allow another entry from the same Google Account. Participants were ensured the confidentiality and privacy of their responses to reduce potential bias introduced by self-reported data.

\section{Tool development and measures}

We developed the questionnaire through participatory discussion with the research team of participating countries. Through Zoom meetings, the principal author discussed research objectives and methodology with all country representatives. The questionnaire was initially developed in English and translated into local languages. Then, the questionnaire was back-translated, pre-tested, and revised by the research team in the individual country. A group of expert panels in the respective countries which included psychiatrists, clinical psychologists, physicians, clinicians and public health experts translated and culturally validated into their national. Pilot testing comprised of 15 participants in each country to test face validity and 50 participants in each country to test the internal consistency. The Cronbach's alpha value ranging from 0.824 to 0.925 indicated that the questionnaire has a good to excellent internal consistency across all countries. It took approximately 10 mins to complete the survey.

The questionnaire had 15 items divided into two sections, namely, Section A had nine items and Section $B$ had six questions regarding factors influencing the acceptability of COVID-19 vaccination. The sociodemographic characteristics of the participants were age (continuous), sex (male, female), place of residence (rural, urban), the education level (illiterate, secondary, postsecondary education, tertiary education), employment status (employed, student, unemployed), marital status (never married, married, widowed/divorced/separated), and family economic status (low, medium, high). The economic status was classified according to income classification from Department of Statistics for each country.

We used yes/no questions to assess the participants' perceived COVID-19 vaccine effectiveness, acceptance, and factors believed to be essential for deciding whether to accept COVID-19 vaccines. Participants were asked whether they think COVID-19 vaccination can effectively prevent and control COVID-19. They were also asked whether they would accept COVID-19 vaccines when they become available. We asked whether the participant agreed that vaccination convenience (methods, frequency, distance to vaccination sites), health providers' advice, and costs of vaccines are essential for deciding whether to accept COVID-19 vaccines. Hesitancy in COVID-19 vaccine uptake was measured by asking whether the participant would take COVID-19 vaccines as soon as they become available in the country.

\section{Statistical analyses}

We used Statistical Product and Service Solutions (SPSS) 26.0 (IBM Corp., Armonk, N.Y., USA) for data analyses. One-sample Kolmogorov-Smirnov test was used to assess the normality of age distribution, and it was nonnormally distributed. Therefore, median and range were used as a measure of central tendency. Categorical variables are presented as frequencies and percentages. Pearson's Chi-square test was used to observe the association between socio-demographics and the COVID-19 vaccine-related variables and between-country differences. The Bonferroni-adjusted post hoc test was applied for significant results in the Pearson's Chi-square tests. After fulfilling the assumptions (relationship between variables and absence of multicollinearity), we conducted binary logistic regression analyses with a backward conditional approach to explore the relationship between vaccine hesitancy (yes, no) and socio-demographic characteristics controlling for the covariates included in the models. All variables associated with vaccine hesitancy in bivariate analyses at a level of $p$ value $<0.05$ were included in the multivariable regression analyses.

\section{Ethics}

Each study country representative obtained ethical clearance. The format of informed consent forms for all selected studies adhered to the guidelines recommended by the SOMREC which, at the minimum, stipulate inclusion of sections on purpose of the research, 
study procedures, discomforts and risks, potential benefits, privacy and confidentiality, compensation for participation, voluntary participation, investigators' contact information for questions about study, and ethics committee contact for questions about rights and welfare of participants.

Table 1 Socio-demographic characteristics of participants $(n=5260)$

\begin{tabular}{lc}
\hline Socio-demographic characteristics & Number (\%) \\
\hline Female & $2660(50.6)$ \\
Urban residence & $3661(69.6)$ \\
Employment status & \\
Employed & $3243(61.7)$ \\
Student & $1826(34.7)$ \\
Unemployed & $191(3.6)$ \\
Education level & \\
$\leq$ Primary & $38(0.7)$ \\
Secondary & $814(15.5)$ \\
Post-secondary & $1484(28.2)$ \\
Tertiary & $2924(55.6)$ \\
Family economic status & \\
Low & $866(16.5)$ \\
Medium & $1944(37.0)$ \\
High & $2450(46.6)$ \\
Marital status & \\
Never married & $2912(55.4)$ \\
Married & $2189(41.6)$ \\
Widowed/divorced/separated & $159(3.0)$ \\
Country of residence & \\
Indonesia & $339(6.4)$ \\
Malaysia & $1273(24.2)$ \\
Myanmar & $300(5.7)$ \\
Philippines & $311(5.9)$ \\
Vietnailand & $2367(45.0)$ \\
\hline
\end{tabular}

\section{Results}

Table 1 shows the socio-demographic characteristics of the participants. A total of 5260 participants completed the questionnaire-339 from Indonesia, 1273 from Malaysia, 300 from Myanmar, 311 from Philippines, 2367 from Thailand, and 670 from Vietnam. The median age of the participants was 30 years (range: 15-83 years). Slightly more than half of the participants were female (50.6\%) and never married (55.4\%). About two-thirds of the participants were employed (61.7\%), and $69.6 \%$ resided in urban areas. More than half of the participants $(55.6 \%)$ had tertiary education. Almost half of the participants $(46.6 \%)$ reported medium family economic status, and $45 \%$ were from Thailand.

As shown in Table 2, 81.2\% of the participants agreed that vaccination could effectively prevent and control COVID-19, and $84.0 \%$ would accept the vaccines when they become available. The majority believed that vaccination convenience $(75.6 \%)$, health providers' advice (83.0\%), and costs of vaccines $(62.8 \%)$ are essential for deciding whether to accept COVID-19 vaccines. However, about half (50.7\%) still expressed their hesitation to take the COVID-19 vaccines.

Table 3 shows that males were significantly more likely to agree that vaccines could effectively prevent and control COVID-19, responded that they would accept the vaccines when they become available, and believed that health providers' advice and costs of vaccines are important for deciding whether to accept COVID-19 vaccines than females. Participants living in urban areas were significantly more likely to agree that vaccines can effectively prevent and control COVID-19, responded that they would accept the vaccines when they become available, and believed that vaccination convenience, health providers' advice, and costs of vaccines are important for deciding whether to accept COVID-19 vaccines than those living in rural areas. Participants living in rural areas were significantly more likely to express hesitancy in receiving COVID-19 vaccines than those living in urban areas.

Table 2 Overall perceived effectiveness, acceptance, and determinants of COVID-19 vaccine uptake decision-making $(n=5260)$

\begin{tabular}{ll}
\hline & Number (\%) \\
\hline Agreed that vaccines are can effectively prevent and control COVID-19 & $4271(81.2)$ \\
Would accept COVID-19 vaccines when available & 4418 (84.0) \\
Believed that vaccination convenience is important for deciding whether to accept vaccines & $3976(75.6)$ \\
Believed that health providers' advice is important for deciding whether to accept COVID-19 vaccines & 4367 (83.0) \\
Believed that costs of the vaccines are important for deciding whether to accept COVID-19 vaccines & 3303 (62.8) \\
No hesitancy in receiving COVID-19 vaccines & 2592 (49.3) \\
\hline
\end{tabular}


Table 3 Perceived effectiveness, acceptance, and determinants of COVID-19 vaccine uptake decision-making by socio-demographic characteristics $(n=5260)$

\begin{tabular}{|c|c|c|c|c|c|c|}
\hline $\begin{array}{l}\text { Socio- } \\
\text { demographic } \\
\text { characteristics }\end{array}$ & $\begin{array}{l}\text { Agreed that } \\
\text { vaccines are } \\
\text { effective to } \\
\text { prevent and } \\
\text { control COVID-19 }\end{array}$ & $\begin{array}{l}\text { Would accept } \\
\text { COVID-19 } \\
\text { vaccines when } \\
\text { available }\end{array}$ & $\begin{array}{l}\text { Believed that } \\
\text { convenience is } \\
\text { important for } \\
\text { people to decide } \\
\text { whether to accept } \\
\text { vaccines }\end{array}$ & $\begin{array}{l}\text { Believed that } \\
\text { health providers' } \\
\text { advice is } \\
\text { important for } \\
\text { people to decide } \\
\text { whether to accept } \\
\text { vaccines }\end{array}$ & $\begin{array}{l}\text { Believed that cost } \\
\text { of the vaccines } \\
\text { is important for } \\
\text { people to decide } \\
\text { whether to accept } \\
\text { vaccines }\end{array}$ & $\begin{array}{l}\text { Hesitant to receive } \\
\text { COVID-19 vaccines }\end{array}$ \\
\hline \multicolumn{7}{|l|}{ Sex } \\
\hline Female & $2088(78.5)$ & 2178 (81.9) & $1991(74.8)$ & $2175(81.8)$ & $1615(60.7)$ & $1342(50.4)$ \\
\hline Male & $2183(84.0)^{\mathrm{a}}$ & $2240(86.2)^{\mathrm{a}}$ & $1985(76.3)$ & $2192(84.3)^{\mathrm{a}}$ & $1690(65.0)^{\mathrm{a}}$ & $1250(48.1)$ \\
\hline$p$ value & $<0.001$ & $<0.001$ & 0.21 & 0.01 & 0.001 & 0.09 \\
\hline \multicolumn{7}{|l|}{ Residential area } \\
\hline Rural & 1187 (74.2) & $1217(76.1)$ & $1016(63.5)$ & $1139(71.2)$ & $766(47.9)$ & $901(56.3)^{a}$ \\
\hline Urban & $3084(84.2)^{\mathrm{a}}$ & $3201(87.4)^{\mathrm{a}}$ & $2960(80.9)^{\mathrm{a}}$ & $3228(88.2)^{\mathrm{a}}$ & $2539(69.4)^{\mathrm{a}}$ & $1691(46.2)$ \\
\hline$p$ value & $<0.001$ & $<0.001$ & $<0.001$ & $<0.001$ & $<0.001$ & $<0.001$ \\
\hline \multicolumn{7}{|l|}{ Education level } \\
\hline$\leq$ Primary & $36(94.7)$ & $35(92.1)$ & $17(44.7)$ & $20(52.6)$ & $5(13.2)$ & $34(89.5)^{\mathrm{a}}$ \\
\hline Secondary & $1151(77.6)$ & $1142(77.0)$ & $1050(70.8)$ & $1090(73.5)$ & $840(56.6)$ & $799(53.9)^{\mathrm{a}}$ \\
\hline Post-secondary & $540(66.3)$ & $531(65.2)$ & $520(63.9)$ & $534(65.6)$ & $422(51.8)$ & $422(51.8)^{\mathrm{a}}$ \\
\hline Tertiary & $2544(87.0)^{\mathrm{a}}$ & $2710(92.7)^{\mathrm{a}}$ & $2389(81.7)^{a}$ & $2722(93.1)^{\mathrm{a}}$ & $2038(69.7)^{\mathrm{a}}$ & $1337(45.7)$ \\
\hline$p$ value & $<0.001$ & $<0.001$ & $<0.001$ & $<0.001$ & $<0.001$ & $<0.001$ \\
\hline \multicolumn{7}{|l|}{ Employment status } \\
\hline Employed & $2429(74.9)$ & $2596(80.0)$ & $2222(68.5)$ & $2515(77.6)$ & $1800(55.5)$ & $1603(49.4)$ \\
\hline Student & $1679(91.9)^{\mathrm{a}}$ & $1653(90.5)^{\mathrm{a}}$ & $1598(87.5)^{\mathrm{a}}$ & $1692(92.7)^{\mathrm{a}}$ & $1386(75.9)^{\mathrm{a}}$ & $871(47.7)$ \\
\hline Unemployed & $163(85.3)$ & $169(88.5)$ & $156(81.7)$ & $160(83.8)$ & $119(62.3)$ & $118(61.8)^{\mathrm{a}}$ \\
\hline$p$ value & $<0.001$ & $<0.001$ & $<0.001$ & $<0.001$ & $<0.001$ & $<0.001$ \\
\hline \multicolumn{7}{|l|}{ Marital status } \\
\hline $\begin{array}{l}\text { Widowed/ } \\
\text { divorced/sepa- } \\
\text { rated }\end{array}$ & $111(69.8)$ & $120(75.5)$ & $95(59.7)$ & $115(72.3)$ & $96(60.4)$ & $88(55.4)$ \\
\hline Married & $1692(77.3)$ & $1813(82.8)$ & $1540(70.4)$ & $1753(80.1)$ & $1225(56.0)$ & $1069(48.8)$ \\
\hline Single & $2468(84.8)^{\mathrm{a}}$ & $2485(85.3)^{\mathrm{a}}$ & $2341(80.4)^{\mathrm{a}}$ & $2499(85.8)^{\mathrm{a}}$ & $1984(68.1)^{\mathrm{a}}$ & $1435(49.3)$ \\
\hline$p$ value & $<0.001$ & $<0.001$ & $<0.001$ & $<0.001$ & $<0.001$ & 0.29 \\
\hline \multicolumn{7}{|c|}{ Family economic status } \\
\hline High & $751(86.7)^{\mathrm{a}}$ & $807(93.2)^{a}$ & $600(69.3)$ & $733(84.6)^{\mathrm{a}}$ & $423(48.8)$ & $459(53.1)^{\mathrm{a}}$ \\
\hline Low & $1507(77.5)$ & $1535(79.0)$ & $1474(75.8)$ & $1574(81.0)$ & $1283(66.0)^{\mathrm{a}}$ & $1013(52.1)^{\mathrm{a}}$ \\
\hline Medium & $2013(82.2)$ & $2076(84.7)$ & $1902(77.6)^{a}$ & $2060(84.1)$ & $1599(65.3)$ & $1120(45.7)$ \\
\hline$p$ value & $<0.001$ & $<0.001$ & $<0.001$ & 0.009 & $<0.001$ & $<0.001$ \\
\hline \multicolumn{7}{|l|}{ Country of residence } \\
\hline Indonesia & $306(7.2)$ & $264(6.0)$ & $339(8.5)$ & $315(7.2)$ & $181(5.5)$ & $264(10.2)$ \\
\hline Malaysia & $1221(28.6)$ & $1223(27.7)$ & $1218(30.6)$ & $1241(28.4)$ & $1162(35.2)$ & $487(18.8)$ \\
\hline Myanmar & $255(6.0)$ & $271(6.1)$ & $260(6.5)$ & $259(5.9)$ & $211(6.4)$ & $187(7.2)$ \\
\hline Philippines & $277(6.5)$ & $254(5.7)$ & $289(7.3)$ & $292(6.7)$ & $254(7.7)$ & $106(4.1)$ \\
\hline Thailand & $1624(38.0)$ & $1806(40.9)$ & $1550(39.0)$ & $1797(41.1)$ & 1385 (41.9) & $976(37.7)$ \\
\hline Vietnam & $588(13.8)$ & $600(13.6)$ & $320(8.0)$ & $463(10.6)$ & $112(3.4)$ & $572(22.1)$ \\
\hline$p$ value & $<0.001$ & $<0.001$ & $<0.001$ & $<0.001$ & $<0.001$ & $<0.001$ \\
\hline
\end{tabular}

${ }^{a}$ Bonferroni adjusted post-hoc comparisons (exact $p$ values are mentioned in the text)

Participants with tertiary education were significantly more likely to agree that vaccines can effectively prevent and control COVID-19, responded that they would accept the vaccines when they become available, and believed that vaccination convenience, health providers' advice, and costs of vaccines are important for deciding 
whether to accept COVID-19 vaccines than participants with lower education. Participants with lower education were significantly more likely to express hesitancy in receiving COVID-19 vaccines than participants with tertiary education. Compared to unemployed and employed participants, students were significantly more likely to agree that vaccines can effectively prevent and control COVID-19, responded that they would accept the vaccines when they become available, and believed that vaccination convenience, health providers' advice, and costs of vaccines are important for deciding whether to accept COVID-19 vaccines. Unemployed participants were significantly more likely to express hesitancy in receiving COVID-19 vaccines than students and employed participants.

Never-married participants were significantly more likely to agree that vaccines can effectively prevent and control COVID-19, responded that they would accept the vaccines when they become available, and believed that vaccination convenience, health providers' advice, and costs of vaccines are important for deciding whether to accept COVID-19 vaccines than married and widowed, divorced or separated participants. Participants with a high family economic status were significantly more likely to agree that vaccines can effectively prevent and control COVID-19, responded that they would accept the vaccines when they become available, and believed that health providers' advice is important for deciding whether to accept COVID-19 vaccines than participants with a low and medium family economic status. Participants with a medium family economic status were significantly more likely to believe that vaccination convenience is important for deciding whether to accept COVID-19 vaccines than participants with a low and high family economic status. Participants with a low family economic status were significantly more likely to believe that vaccine costs are important for deciding whether to accept COVID-19 vaccines than participants with a medium and high family economic status. Participants with a low and high family economic status were significantly more likely to express hesitancy in receiving COVID-19 vaccines than participants with a medium family economic status. The differences between countries were all statistically significant.

Table 4 presents the association between countries and COVID-19 vaccine effectiveness, acceptance, convenience, recommendation, price, and hesitancy. Results showed a significant association between all vaccine factors and countries $(p<0.001)$, respectively.

Table 4 Association between COVID-19 (effectiveness, acceptance, convenience, recommendation, price, and hesitancy) with Countries

\begin{tabular}{|c|c|c|c|c|c|c|c|}
\hline \multirow[t]{2}{*}{ COVID-19 } & \multicolumn{7}{|l|}{ Countries } \\
\hline & $\begin{array}{l}\text { Indonesia } \\
N=339 \\
n(\%)\end{array}$ & $\begin{array}{l}\text { Malaysia } \\
N=1273 \\
n(\%)\end{array}$ & $\begin{array}{l}\text { Myanmar } \\
N=300 \\
n(\%)\end{array}$ & $\begin{array}{l}\text { Philippines } \\
N=311 \\
n(\%)\end{array}$ & $\begin{array}{l}\text { Thailand } \\
N=2367 \\
n(\%)\end{array}$ & $\begin{array}{l}\text { Vietnam } \\
N=670 \\
n(\%)\end{array}$ & $p$ value \\
\hline Effectiveness & & & & & & & $<0.001^{\mathrm{a}}$ \\
\hline No & $33(3.3)$ & $52(5.3)$ & $45(4.6)$ & $34(3.4)$ & $743(75.1)$ & $82(8.3)$ & \\
\hline Yes & $306(7.2)$ & $1221(28.6)$ & $255(6.0)$ & $277(6.5)$ & $1624(38.0)$ & $588(13.8)$ & \\
\hline Acceptance & & & & & & & $<0.001^{\mathrm{a}}$ \\
\hline No & $75(8.9)$ & $50(5.9)$ & $29(3.4)$ & $57(6.8)$ & $561(66.6)$ & $70(8.3)$ & \\
\hline Yes & $264(6.0)$ & $1223(27.7)$ & $271(6.1)$ & $254(5.7)$ & $1806(40.9)$ & $600(13.6)$ & \\
\hline Convenience & & & & & & & $<0.001^{\mathrm{a}}$ \\
\hline No & $0(0.0)$ & $55(4.3)$ & $40(3.1)$ & $22(1.7)$ & $817(63.6)$ & $350(27.3)$ & \\
\hline Yes & $339(8.5)$ & 1218 (30.6) & $260(6.5)$ & $289(7.3)$ & $1550(39.0)$ & $320(8.0)$ & \\
\hline Recommendation & & & & & & & $<0.001^{\mathrm{a}}$ \\
\hline No & $24(2.7)$ & $32(3.6)$ & $41(4.6)$ & $19(2.1)$ & $570(63.8)$ & $207(23.2)$ & \\
\hline Yes & $315(7.2)$ & $1241(28.4)$ & $259(5.9)$ & $292(6.7)$ & $1797(41.1)$ & $463(10.6)$ & \\
\hline Price & & & & & & & $<0.001^{\mathrm{a}}$ \\
\hline No & $158(8.1)$ & $111(5.7)$ & $89(4.6)$ & $57(2.9)$ & $982(50.2)$ & $588(28.5)$ & \\
\hline Yes & $181(5.5)$ & $1162(35.2)$ & $211(6.4)$ & $254(7.7)$ & $1385(41.9)$ & $112(3.4)$ & \\
\hline Hesitancy & & & & & & & $<0.001^{\mathrm{a}}$ \\
\hline No & $75(2.8)$ & $786(29.5)$ & $113(4.2)$ & $205(7.7)$ & $1391(52.1)$ & $98(3.7)$ & \\
\hline Yes & $264(10.2)$ & 487 (18.8) & 187 (7.2) & $106(4.1)$ & $976(37.7)$ & $572(22.1)$ & \\
\hline
\end{tabular}

a Significant at $5 \%$ level of significance 
Table 5 shows factors associated with hesitancy in COVID-19 vaccine uptake in the logistic regression model. After adjustment, having no hesitation was significantly associated with living in rural areas (AOR: 1.40, 95\% CI: 1.24-1.59), lower education (AOR: 7.74, 95\% CI: $2.72-22.05$ for illiterate, AOR: 1.19, 95\% CI: 1.01-1.41 for secondary education, and AOR: $1.29,95 \%$ CI: $1.13-1.47$ for post-secondary relative to tertiary education), family economic status (AOR: 1.23, 95\% CI 1.09-1.39 for lower and AOR: 1.39, 95\% CI: 1.19-1.63 for higher relative to medium-income), and employment status (AOR: 1.21, 95\% CI 1.03-1.42 for being employed and AOR: 1.85, 95\% CI: $1.14-2.60$ for being unemployed relative to being students). Compared to those from Philippines, participants from Indonesia (AOR: 6.81, 95\% CI: 4.81 9.64), Myanmar (AOR 3.20, 95\% CI: 2.30-4.46), Thailand (AOR: 1.06, 95\% CI: $1.06-$ 1.74), and Vietnam (AOR: 11.28, 95\% CI: 8.22-1.50) were significantly more likely to express no hesitancy in receiving COVID-19 vaccines.

Table 5 Factors associated with hesitancy in COVID-19 vaccine uptake in logistic regression model $(n=5260)$

\begin{tabular}{|c|c|c|}
\hline Variables in the model & AOR $(95 \% \mathrm{Cl})$ & $P$ value \\
\hline Age & $0.99(0.98-0.99)$ & $<0.001$ \\
\hline \multicolumn{3}{|l|}{ Residential area } \\
\hline Urban & Reference & \\
\hline Rural & $1.40(1.24-1.59)$ & \\
\hline \multicolumn{3}{|l|}{ Education level } \\
\hline Tertiary & Reference & \\
\hline$\leq$ Primary & $7.74(2.72-22.05)$ & $<0.001$ \\
\hline Secondary & $1.19(1.01-1.41)$ & 0.04 \\
\hline Post-secondary & $1.29(1.13-1.47)$ & $<0.001$ \\
\hline \multicolumn{3}{|l|}{ Family economic status } \\
\hline Medium & Reference & \\
\hline Low & $1.23(1.09-1.39)$ & 0.001 \\
\hline High & $1.39(1.19-1.63)$ & $<0.001$ \\
\hline \multicolumn{3}{|l|}{ Employment status } \\
\hline Student & Reference & \\
\hline Employed & $1.21(1.03-1.42)$ & 0.02 \\
\hline Unemployed & $1.85(1.14-2.60)$ & 1.85 \\
\hline \multicolumn{3}{|l|}{ Country of residence } \\
\hline Philippines & Reference & \\
\hline Indonesia & $6.81(4.81-9.64)$ & $<0.001$ \\
\hline Malaysia & $1.20(0.92-1.56)$ & 0.17 \\
\hline Myanmar & $3.20(2.30-4.46)$ & $<0.001$ \\
\hline Thailand & $1.36(1.06-1.74)$ & 0.02 \\
\hline Vietnam & $11.28(8.22-1.50)$ & $<0.001$ \\
\hline
\end{tabular}

AOR, adjusted odd ratio; $\mathrm{Cl}$, confidence interval

\section{Discussion}

Our multi-country study of six countries of the Southeast Asian region provides essential insight into the perception of COVID-19 vaccines, acceptability, hesitancy, and factors associated with hesitation in the vaccine uptake. Most participants believed that vaccination effectively prevents and controls COVID-19 and would accept COVID-19 vaccines when they become available. They agreed that health providers' advice, vaccination convenience, and vaccine costs are essential for deciding whether to accept COVID-19 vaccines. However, about half expressed their hesitancy to receive the COVID-19 vaccines. The highest rate of vaccine hesitancy has been observed in Russia (72\%), whereas the lowest in Vietnam (27\%) [9].

We have identified several socio-demographic factors associated with hesitancy in COVID-19 vaccine uptake, including age, residential area, education level, family economic status, employment status, and country of residence. The existing studies from Southeast Asian countries $[19,42]$ also show that the older populations are more likely to express their hesitation in receiving the vaccines than the younger populations. In addition, participants from low and high family economic backgrounds were more likely to show uncertainty in receiving COVID-19 vaccines than those with medium family financial status. Previous studies have reported several factors that may explain the populations' hesitancy in COVID-19 vaccine acceptance. The factors include lower economic level [43], concerns about the possibly damaging outcome of the COVID-19 vaccines to developing babies in the womb [44], conspiracy beliefs regarding the COVID-19 vaccine might cause infertility and miscarriages [45], and less perceived susceptibility [46].

Place of residence was one of the significant factors that may determine COVID-19 acceptance and uptake. In this study, urban residents were more likely to support COVID-19 vaccines' effectiveness and uptake. They were more likely to believe that vaccination convenience, advice from health providers, and vaccine costs are important for people deciding whether to receive the vaccines than rural residents. Similarly, rural residents had a higher level of hesitation in the COVID-19 vaccine than urban residents. These findings are similar to other studies conducted in Bangladesh and Philippines [14]. Higher levels of accessibility, affordability, education, and standard of living are related to vaccine acceptability among people living in urban areas. Having more exposure to the different sources of information, urban residents can create more comprehensive access to more accurate information through media and other reliable sources regarding vaccines. Exposure to negative information about the vaccines was associated with a high 
level of vaccine hesitancy in Philippines [47]. There is the need for accurate information on the COVID-19 vaccine, which is very important for its proper management [48].

Education level was also associated with hesitancy in COVID-19 uptake in this study. People with tertiary education were more likely to support COVID-19 vaccines' effectiveness and uptake than those with lower education. They were also more likely to believe that vaccination convenience, health providers' advice, and costs of vaccines are important for people to decide whether to receive COVID-19 vaccines. Similarly, people with lower education more hesitated when asked whether they would accept COVID-19 vaccines than people with tertiary education. Higher educated populations generally possess better knowledge about the vaccines and vaccination process [49], which creates more heightened awareness regarding the risks and benefits of the vaccination. The level of hesitancy decreases when the level of knowledge about the COVID-19 vaccine and its associated processes increases [14]. Better knowledge of the vaccination process was a significant factor associated with vaccine hesitancy in previous studies in Bangladesh, Malaysia, India, Kenya, Myanmar, and Thailand [14, 16, 50].

\section{Strengths and limitations}

To our knowledge, this is the first multi-country study examining the factors associated with COVID-19 vaccine hesitancy in Southeast Asia. We collected data from a large sample in six countries assessing vaccine effectiveness, acceptance, and hesitation in various populations from different contexts, cultures, and backgrounds. Despite these strengths, this study has several limitations. Response biases could be one of the critical limitations of the study. In addition, data were collected using the snowball technique, which could hamper the heterogeneity in the sample. Another significant limitation is the representativeness of the sample population. A higher proportion of the sampled population were highly educated and residing in urban areas. Since, hesitancy was slightly lower among educated and urban residents, overrepresentation of these groups could lead to underestimation of vaccine hesitancy.

\section{Conclusions}

This study provides a crucial understanding of the populations' perception required to design effective COVID19 vaccine programs in Southeast Asia. Participants in this multi-country study generally showed their optimistic perception of COVID-19 vaccines' effectiveness and willingness to receive them. However, about half of them still expressed their hesitancy in getting vaccinated. The hesitation was associated with several socioeconomic factors and varied by country. COVID-19 vaccination promotion campaign should consider these factors as essential elements for increasing vaccine uptake in the populations in the region. Further studies on COVID-19 vaccine acceptance and hesitancy should be a priority. We can use the studies' findings to inform contextualized vaccination programs and information-sharing, ultimately resulting in increased confidence in and uptake of the available vaccines.

\section{Acknowledgements \\ The authors would like to thank the participants of this study.}

\section{Authors' contributions}

RRM conceived and designed the study. RRM and MZA performed validation and reliability of the questionnaire. RRM, KJ, KS, NTP, TR, EMF, AMB, YA, SMB collected the data. WS and RRM conducted the statistical analysis and interpretation of the findings. RRM, SY, MZA, WS, MYE, and SA wrote the initial draft. RRM, WS, MZA, SS and SY critically reviewed and finalized the manuscript. All authors read and approved the final version of this manuscript.

Funding

The authors received no funding for this work.

Availability of data and materials

The data relating to this manuscript are available upon request.

\section{Declarations}

Ethic approval and consent to participate

Each study country representative obtained ethical clearance. The format of informed consent forms for all selected studies adhered to the guidelines recommended by the SOMREC which, at the minimum, stipulate inclusion of sections on purpose of the research, study procedures, discomforts and risks, potential benefits, privacy and confidentiality, compensation for participation, voluntary participation, investigators' contact information for questions about study, and ethics committee contact for questions about rights and welfare of participants.

\section{Consent for publication}

Not applicable.

\section{Competing interests}

The authors declare that they have no competing interests.

\section{Author details}

${ }^{1}$ Department of Community Medicine, International Medical School, Management and Science University, Shah Alam, Selangor, Malaysia. ${ }^{2}$ Department of Community Medicine, Faculty of Medicine, Asia Metropolitan University, Masai, Johor, Malaysia. ${ }^{3}$ Global Public Health, Jeffrey Cheah School of Medicine and Health Sciences, Monash University Malaysia, Jalan Lagoon Selatan, 47500 Subang Jaya, Selangor, Malaysia. ${ }^{4}$ Department of Community Medicine and Public Health, College of Medicine, Majmaah University, Almajmaah 11952, Saudi Arabia. ${ }^{5}$ Azra Naheed Medical College, Superior University, Lahore, 54000, Pakistan. ${ }^{6}$ Department of Population Sciences, University of Dhaka, Dhaka, Bangladesh. ${ }^{7}$ Department of Nursing, Nepal Health Research and Innovation Foundation, Lalitpur, Province Bagmati, Nepal. ${ }^{8}$ College of Innovative Business and Accountancy, Dhurakij Pundit University, Bangkok, Thailand. ${ }^{9}$ Faculty of Economics and Investment, Bangkok University, Bangkok, Thailand. ${ }^{10}$ International University, Ho Chi Minh City, Vietnam. ${ }^{11}$ Vietnam National University Ho Chi Minh City, Ho Chi Minh City, Vietnam. ${ }^{12}$ Department of Public Health, Faculty of Medicine and Faculty of Graduate Studies, Universitas Islam Bandung, Bandung, Indonesia. ${ }^{13}$ Department of Pharmacy, Faculty of Pharmacy, San Pedro College, Davao City, Philippines. ${ }^{14}$ College of Nursing, Saint Alexius College, Koronadal, South Cotabato, Philippines. ${ }^{15}$ Medical Statistics Division, Department of Medical Research, Pyin Oo Lwin, Myanmar. ${ }^{16}$ Institute for Population and Social Research, Mahidol University, Bangkok, Thailand. ${ }^{17}$ Department of Economics, Sridora Caculo College, 
Mapusa, Goa, India. ${ }^{18}$ Kabul University of Medical Sciences, Kabul, Afghanistan. ${ }^{19}$ Department of Pharmaceutical and Health Service Research, Nepal Health Research and Innovation Foundation, Lalitpur, Province Bagmati, Nepal. ${ }^{20}$ Saw Swee Hock School of Public Health, National University of Singapore and National University Health System, Singapore, Singapore. ${ }^{21}$ KHANA Center for Population Health Research, Phnom Penh, Cambodia. ${ }^{22}$ Center for Global Health Research, Touro University California, Vallejo, California, USA.

Received: 14 September 2021 Accepted: 20 December 2021 Published online: 05 January 2022

\section{References}

1. Omer SB, Yildirim I, Forman HP. Herd immunity and implications for SARSCoV-2 control. JAMA. 2020;324(20):2095-6.

2. Nicola M, Alsafi Z, Sohrabi C, Kerwan A, Al-Jabir A, losifidis C, Agha M, Agha R. The socio-economic implications of the coronavirus pandemic (COVID-19): a review. Int J Surg. 2020;78:185-93.

3. Randolph HE, Barreiro LB. Herd immunity: understanding COVID-19. Immunity. 2020;52(5):737-41.

4. Ehreth J. The value of vaccination: a global perspective. Vaccine. 2003;21(27-30):4105-17.

5. Hajj Hussein I, Chams N, Chams S, El Sayegh S, Badran R, Raad M, Gerges-Geagea A, Leone A, Jurjus A. Vaccines through centuries: major cornerstones of global health. Front Public Health. 2015;3:269.

6. Rodrigues CMC, Plotkin SA. Impact of vaccines; health, economic and social perspectives. Front Microbiol. 2020;11:1526.

7. Larson HJ, Jarrett C, Eckersberger E, Smith DM, Paterson P. Understanding vaccine hesitancy around vaccines and vaccination from a global perspective: a systematic review of published literature, 2007-2012. Vaccine. 2014;32(19):2150-9

8. Khatiwada AP, Shrestha N, Shrestha S. Will COVID-19 lead to a resurgence of vaccine-preventable diseases? Infect Drug Resist. 2021;14:119-24.

9. Rozek L, Jones P, Menon A, Hicken A, Apsley S, King E. Understanding vaccine hesitancy in the context of COVID-19: the role of trust and confidence in a seventeen-country survey. Int J Public Health. 2021:66:48.

10. Wiysonge CS, Ndwandwe D, Ryan J, Jaca A, Batouré O, Anya B-PM Cooper S. Vaccine hesitancy in the era of COVID-19: could lessons from the past help in divining the future? Hum Vaccines Immunother. 2021; $1-3$.

11. Marzo RR, Ahmad A, Abid K, Khatiwada AP, Ahmed A, Kyaw TM, Abidin IBZ, Srithar M, Sinnathamby S, Sarvasundram AP, et al. Factors influencing the acceptability of COVID-19 vaccination: a cross-sectional study from Malaysia. Vacunas. 2021. https://doi.org/10.1016/j.vacun.2021.07.007.

12. MacDonald NE. Vaccine hesitancy: definition, scope and determinants. Vaccine. 2015;33(34):4161-4.

13. Lin C, Tu P, Beitsch LM. Confidence and receptivity for COVID-19 vaccines: a rapid systematic review. Vaccines (Basel). 2020:9(1):16.

14. Hossain MB, Alam MZ, Islam MS, Sultan S, Faysal MM, Rima S, Hossain MA Mamun AA. COVID-19 vaccine hesitancy among the adult population in Bangladesh: a nationally representative cross-sectional survey. medRxiv. 2021:2021.2004.2023.21255844

15. Sallam M. COVID-19 vaccine hesitancy worldwide: a concise systematic review of vaccine acceptance rates. Vaccines. 2021:9(2):160.

16. Bono SA, de Villela FME, Siau CS, Chen WS, Pengpid S, Hasan MT, Sessou P, Ditekemena JD, Amodan BO, Hosseinipour MC, et al. Factors affecting COVID-19 vaccine acceptance: an international survey among low- and middle-income countries. Vaccines. 2021:9(5):515.

17. Vicente NE, Cordero DA. In the service of the Filipino: the role of Catholic higher education institutions in promoting COVID-19 vaccines in the Philippines. J Public Health (Oxf). 2021;43(2):e377-8.

18. Soares P, Rocha JV, Moniz M, Gama A, Laires PA, Pedro AR, Dias S, Leite A, Nunes C. Factors associated with COVID-19 vaccine hesitancy. Vaccines. 2021;9(3):300

19. Huynh G, Tran T, Nguyen H, Pham L. COVID-19 vaccination intention among healthcare workers in Vietnam. Asian Pac J Trop Med. 2021;14(4):159-64.

20. Lin Y, Hu Z, Zhao Q, Alias H, Danaee M, Wong LP. Understanding COVID19 vaccine demand and hesitancy: a nationwide online survey in China. PLoS Negl Trop Dis. 2020;14(12):e0008961.
21. Mercadante AR, Law AV. Will they, or won't they? Examining patients' vaccine intention for flu and COVID-19 using the Health Belief Model. Res Social Adm Pharm. 2021:17(9):1596-605.

22. Hossain MB, Alam MZ, Islam MS, Sultan S, Faysal MM, Rima S, Hossain MA, Mamun AA. Health belief model, theory of planned behavior, or psychological antecedents: what predicts COVID-19 vaccine hesitancy better among the Bangladeshi adults? Front Public Health. 2021;9:1172.

23. Ruiz JB, Bell RA. Predictors of intention to vaccinate against COVID-19: results of a nationwide survey. Vaccine. 2021:39(7):1080-6.

24. Paul E, Steptoe A, Fancourt D: Anti-vaccine attitudes and risk factors for not agreeing to vaccination against COVID-19 amongst 32,361 UK adults: implications for public health communications. medRxiv. 2020:2020.2010.2021.20216218.

25. Khan YH, Mallhi TH, Alotaibi NH, Alzarea Al, Alanazi AS, Tanveer N, Hashmi FK. Threat of COVID-19 vaccine hesitancy in Pakistan: the need for measures to neutralize misleading narratives. Am J Trop Med Hyg. 2020;103(2):603-4.

26. Dubé E, Vivion M, MacDonald NE. Vaccine hesitancy, vaccine refusal and the anti-vaccine movement: influence, impact and implications. Expert Rev Vaccines. 2015;14(1):99-117.

27. Sallam M, Dababseh D, Eid H, Al-Mahzoum K, Al-Haidar A, Taim D, Yaseen A, Ababneh NA, Bakri FG, Mahafzah A. High rates of COVID-19 vaccine hesitancy and its association with conspiracy beliefs: a study in Jordan and Kuwait among other Arab countries. Vaccines (Basel). 2021;9(1):42.

28. Latkin CA, Dayton L, Yi G, Colon B, Kong X. Mask usage, social distancing, racial, and gender correlates of COVID-19 vaccine intentions among adults in the US. PLoS ONE. 2021;16(2):e0246970.

29. Momplaisir F, Haynes N, Nkwihoreze H, Nelson M, Werner RM, Jemmott J. Understanding drivers of COVID-19 vaccine hesitancy among blacks. Clin Infect Dis. 2021;73:1784

30. Bhuvan KC, Shrestha R, Leggat PA, Ravi Shankar P, Shrestha S. Safety of air travel during the ongoing COVID-19 pandemic. Travel Med Infect Dis. 2021:43:102103-102103.

31. Neumann-Böhme S, Varghese NE, Sabat I, Barros PP, Brouwer W, van Exel J, Schreyögg J, Stargardt T. Once we have it, will we use it? A European survey on willingness to be vaccinated against COVID-19. Eur J Health Econ. 2020;21(7):977-82.

32. Rhodes A, Hoq M, Measey M-A, Danchin M. Intention to vaccinate against COVID-19 in Australia. Lancet Infect Dis. 2021;21(5):e110-e110.

33. Sah R, Shrestha S, Mehta R, Sah SK, Rabaan AA, Dhama K, RodriguezMorales AJ. AZD1222 (Covishield) vaccination for COVID-19: experiences, challenges, and solutions in Nepal. Travel Med Infect Dis. 2021;40:101989-101989.

34. Shrestha S, Khatri J, Shakya S, Danekhu K, Khatiwada AP, Sah R, Kc B, Paudyal V, Khanal S, Rodriguez-Morales AJ. Adverse events related to COVID-19 vaccines: the need to strengthen pharmacovigilance monitoring systems. Drugs Therapy Perspect. 2021;37(8):376-82.

35. Kothari A, Pfuhl G, Schieferdecker D, Harris CT, Tidwell C, Fitzpatrick KM, Godleski S, Sanjay S. The barrier to vaccination is not vaccine hesitancy: patterns of COVID-19 vaccine acceptance over the course of the pandemic in 23 countries. medRxiv. 2021:2021.2004.2023.21253857.

36. King I, Heidler P, Marzo RR. The long and winding road: uptake, acceptability, and potential influencing factors of COVID-19 vaccination in Austria. Vaccines. 2021;9(7):790.

37. Center for Strategic and International Studies (CSIS). Southeast Asia Covid-19 Tracker. 2021. https://www.csis.org/programs/southeast-asiaprogram/projects/southeast-asia-covid-19-tracker.

38. Kamberi F, Sinaj E, Jaho J, Subashi B, Sinanaj G, Jaupaj K, Stramarko Y, Arapi P, Dine L, Gurguri A, et al. Impact of COVID-19 pandemic on mental health, risk perception and coping strategies among health care workers in Albania-evidence that needs attention. Clin Epidemiol Global Health. 2021:12:100824.

39. Htay MNN, Marzo RR, Bahari R, AlRifai A, Kamberi F, El-Abasiri RA, Nyamache JM, Hlaing HA, Hassanein M, Moe S, et al. How healthcare workers are coping with mental health challenges during COVID-19 pandemic?a cross-sectional multi-countries study. Clin Epidemiol Global Health. 2021;11:100759.

40. Marzo RR, Ismail Z, Nu Htay MN, Bahari R, Ismail R, Villanueva EQ, Singh A, Lotfizadeh M, Respati T, Irasanti SN, et al. Psychological distress during pandemic Covid-19 among adult general population: result across 13 countries. Clin Epidemiol Global Health. 2021;10:100708. 
41. Ghatak N, Marzo RR, Saleem SM, Sharma N, Singh A, Bhattacharya S. Impact on routine immunization services during the lockdown period in india: implications and future recommendations. Eur J Mol Clin Med. 2020;7(5):35-40.

42. Syed Alwi SAR, Rafidah E, Zurraini A, Juslina O, Brohi IB, Lukas S. A survey on COVID-19 vaccine acceptance and concern among Malaysians. BMC Public Health. 2021;21(1):1129.

43. Chang W-H. A review of vaccine effects on women in light of the COVID19 pandemic. Taiwanese J Obstet Gynecol. 2020;59:812.

44. Skjefte M, Ngirbabul M, Akeju O, Escudero D, Hernandez-Diaz S, Wyszynski DF, Wu JW. COVID-19 vaccine acceptance among pregnant women and mothers of young children: results of a survey in 16 countries. Eur J Epidemiol. 2021;36(2):197-211.

45. Murewanhema G. Vaccination hesitancy among women of reproductive age in resource-challenged settings: a cause for public health concern. Pan Afri Med J. 2021;38:336.

46. Jahangiry L, Bakhtari F, Sohrabi Z, Reihani P, Samei S, Ponnet K, Montazeri A. Risk perception related to COVID-19 among the Iranian general population: an application of the extended parallel process model. BMC Public Health. 2020;20(1):1571.

47. Migriño J Jr, Gayados B, Birol KRJ, De Jesus L, Lopez CW, Mercado WC, Tolosa J-MC, Torreda J, Tulagan G. Factors affecting vaccine hesitancy among families with children 2 years old and younger in two urban communities in Manila, Philippines. Western Pac Surveill Response J. 2020;11(2):20-6.

48. Khatiwada AP, Shakya S, Shrestha S. Paradigm shift of drug information centers during the COVID-19 pandemic. Drugs Therapy Perspect. 2020;36(9):389-95.

49. Eitze S, Heinemeier D, Schmid-Küpke NK, Betsch C. Decreasing vaccine hesitancy with extended health knowledge: evidence from a longitudinal randomized controlled trial. Health Psychol. 2021;40(2):77-88,

50. Adugna K, Robert K, Asrat Dibaba T, Md Abul K, Thomas D, Heidi L. Determinants of COVID-19 Vaccine Acceptance in Six Lower-and MiddleIncome Countries. Research square; Preprint. 2021.

\section{Publisher's Note}

Springer Nature remains neutral with regard to jurisdictional claims in published maps and institutional affiliations.

Ready to submit your research? Choose BMC and benefit from:

- fast, convenient online submission

- thorough peer review by experienced researchers in your field

- rapid publication on acceptance

- support for research data, including large and complex data types

- gold Open Access which fosters wider collaboration and increased citations

- maximum visibility for your research: over $100 \mathrm{M}$ website views per year

At BMC, research is always in progress.

Learn more biomedcentral.com/submissions 